\title{
Pharmacoeconomic Benefits of Antihypertensive Therapy
}

\author{
Edgar R. Gonzalez, PharmD, FASHP, FASCP
}

\begin{abstract}
BACKGROUND: Effective blood pressure reduction reduces cardiovascular risk and prevents later complications.

OBJECTIVE: To consider the pharmacoeconomic benefits of antihypertensive therapy.

SUMMARY: Every managed care pharmacist should consider the balance of cost and benefit of antihypertensive therapies, ensuring that best treatment options for patients with the lowest cost to the health care system are available and implemented. Pharmacists must also evaluate the direct and indirect cost associated with risk reduction for stroke and cardiovascular disease.
\end{abstract}

CONCLUSION: Using an interdisciplinary approach to hypertension treatment, pharmacists can assume a major role in detection, management, and control of hypertensive patients. As the medical teams' drug expert, they will be expected to recommend best treatment options for effective blood pressure control and cardiovascular risk reduction.

KEYWORDS: Pharmacoeconomic, Blood pressure, Cardiovascular disease, Hypertension, Metabolic syndrome, Nebivolol, Quality of life

J Manag Care Pharm. 2007;13(5):S20-S21

\section{Author}

EDGAR R. GONZALEZ, PharmD, FASHP, FASCP, is president, Capital Pharmacy Consultants, Mechanicsville, Virginia.

AUTHOR CORRESPONDENCE: Edgar R. Gonzalez, PharmD, FASHP, FASCP, President, Capital Pharmacy Consultants, 8315 Corbin Braxton Ln, Mechanicsville, VA 23111. Tel: (804)399-8482; Fax: (804) 799-3180; E-mail:ergonzalez@cpcllc.com

Copyright $@ 2007$, Academy of Managed Care Pharmacy. All rights reserved. $\square$ ffective blood pressure (BP) reduction reduces cardiovascular risk and prevents later complications. Every managed care pharmacist needs to consider the balance of cost and benefit, ensuring that best treatment options for patients with the lowest cost to the health care system are available and employed. We also must be careful to evaluate the direct and indirect costs associated with risk reduction for stroke and cardiovascular disease (CVD).

\section{Cardiovascular Disease: The Costs}

The National Institutes of Health provides a staggering statistic for the cost of cardiac disease in the United States. If one looks at coronary heart disease, the direct and indirect costs are approximately $\$ 152$ billion. Stroke management costs approximately $\$ 63$ billion, and hypertension and heart failure cost $\$ 66$ billion and $\$ 33$ billion, respectively. The emphasis on preventive measures in coronary artery disease and patients with multiple risk factors for stroke and heart failure is well placed. ${ }^{1}$

To get a sense of the 10-year risk of fatal CVD with and without treatment with beta-blocker therapy and savings associated with beta-blocker therapy, Kaltwasser and colleagues ${ }^{2}$ followed 8,682 hypertensive patients who received nebivolol $5 \mathrm{mg} /$ day. When a cardiovascular death occurred, they determined if the patient had been treated with a beta-blocker. The expected 10-year mortality rate from the Framingham Heart Study estimates that $30 \%$ of males and $36 \%$ of females die. This study found that 154 male deaths and 159 female deaths could have been avoided by beta-receptor blockade.

Calculating using the euro as a basis, these investigators examined economic impact. The table shows the cost per event and the total value of missed savings: 2.5 million euros or U.S.\$3.2 million. ${ }^{2}$ These data show that nebivolol provides cost-effective therapy for patients with hypertension and coexisting cardiovascular comorbidities.

\section{TABLE Potential Economic Impact of Treatment With Nebivolol 5 mg/Day}

\begin{tabular}{l|c|c|c|c|c}
\hline \multirow{2}{*}{ Event } & \multirow{2}{*}{$\begin{array}{c}\text { Cases } \\
\text { Avoided }\end{array}$} & $\begin{array}{c}\text { Cost per } \\
\text { Event (Euro) }\end{array}$ & $\begin{array}{c}\text { Cost Avoided } \\
\text { (Euro) }\end{array}$ & $\begin{array}{c}\text { Cost per } \\
\text { Event (Euro) }\end{array}$ & $\begin{array}{c}\text { Cost Avoided } \\
\text { (Euro) }\end{array}$ \\
\hline Stroke & 150 & 8,620 & $1,013,323$ & 2,285 & 268,613 \\
\hline CHD & 94 & 19,962 & $1,470,555$ & 2,250 & 165,752 \\
\hline Total & & & $2,483,878$ & & 434,365 \\
\hline
\end{tabular}

Only inpatient costs were considered.

Hospitalization costs (2004 values) were converted to the euro.

Kaltwasser MT. Am J Cardiovasc Drugs. 2005.²

$\mathrm{CHD}=$ coronary heart disease. 
Patients often believe that any asymptomatic disease and CVD specifically requires treatment that is often more problematic and more painful than the disease itself. Increasing the number of medications on the regimen or number of doses per day complicates matters further. The average patient with hypertension needs 2 to 3 antihypertensives to reach and maintain BP control. ${ }^{3}$ Oncedaily hypertensive therapy can be quite helpful.

\section{Maintaining Quality of Life}

Must a good antihypertensive effect change quality of life? Researchers compared nebivolol $5 \mathrm{mg}$ and the angiotensin II receptor blocker losartan $50 \mathrm{mg}$ in a double-blind, randomized, parallel study of 314 patients with hypertension over 12 weeks. Both drugs were given once daily. If diastolic response was inadequate after 6 weeks, they added $12.5 \mathrm{mg}$ of hydrochlorothiazide once daily. The drugs' effect on systolic BP was similar, but nebivolol decreased diastolic BP to a greater degree than did losartan. Significantly more losartan-treated patients required supplementary hydrochlorothiazide to achieve BP control than did those treated with nebivolol, thus increasing the number of drugs they were taking. Patients reported similar quality of life (including sexual function) at 6 and 12 weeks. Headache occurred more frequently in the losartan arm. ${ }^{4}$ Use of nebivolol may allow monotherapy to a greater extent, improving adherence and reducing copayment burden.

Quality improvement programs can help with adherence issues. Fonarow et al. organized pharmacists and nurses to promote appropriate medications for heart failure patients and to work with hospitalized patients before discharge. ${ }^{5}$ Called the Cardiac Hospitalization Atherosclerosis Management Program (CHAMP), it promoted initiation of aspirin, cholesterol-lowering medication, beta-blocker, and angiotension-converting enzyme inhibitor (ACEI) therapies. Hospital staff also counseled patients about diet and exercise at the time of hospital discharge. Treatment rates and clinical outcome were compared in patients discharged after myocardial infarction (MI) in the 2-year periods before and after program implementation. As a consequence of this intervention, aspirin use increased from $68 \%$ to $92 \%$, beta-blocker use increased from $12 \%$ to $62 \%$, ACEI use escalated from $6 \%$ to $58 \%$, and statin use went from $6 \%$ to $86 \%$. These improvements were sustained during the 6- to 18-month period after hospital discharge. A larger proportion of post-CHAMP patients (58\%) lowered their low-density lipoprotein cholesterol to less than $100 \mathrm{mg} / \mathrm{dL}$ compared with only $6 \%$ of patients in the pre-CHAMP group. Recurrent MI and 1-year mortality also fell. Enhancing compliance is critical, as is selection of the appropriate therapy for these patients.

\section{Summary}

Managed care pharmacists can help patients with multiple risk factors and hypertension in several ways. Healthy People 2010 goals and Health Plan Employer Data Information Set 2006 measures for hypertension will require a much more aggressive approach to achieve desired BP control rates. That means pharmacists must monitor polypharmacy aggressively and become more vigilant for patient adherence. Using an interdisciplinary approach to hypertension treatment, pharmacists can assume a major role in detection, management, and control of hypertensive patients. They must identify and screen patients who may have metabolic syndrome. Their prescription records and medical databases will be used to track drug adherence, treatment control rates, optimal therapy, and overall compliance to therapy. As the medical teams' drug experts, pharmacists will be expected to recommend best treatment options for effective BP control and cardiovascular risk reduction.

\section{DISCLOSURES}

This article is based on a presentation funded by an educational grant from Forest Pharmaceuticals. The author discloses that he has received honoraria from Forest Pharmaceuticals for participation in this supplement. He discloses the following commercial/ financial relationships through grant/research support, consultant services, speakers bureaus, and/or advisory boards: Amgen and King Pharmaceuticals.

\section{REFERENCES}

1. Rosamond W, Flegal K, Friday G, and Writing Group Members. Heart disease and stroke statistics_2007 update. A report from the American Heart Association Statistics Committee and Stroke Statistics Subcommittee. Circulation. Epub. December 28, 2006;115:1-103.

2. Kaltwasser MT. Economic evaluation of nebivolol in the treatment of hypertension. Am J Cardiovasc Drugs. 2005;5:319-24.

3. Bakris GL, Williams M, Dworkin L, et al. Preserving renal function in adults with hypertension and diabetes: a consensus approach. National Kidney Foundation Hypertension and Diabetes Executive Committees Working Group. Am J Kidney Dis. 2000;36:646-61.

4. Van Bortel LM, Bulpitt CJ, Fici F, et al. Quality of life and antihypertensive effect with nebivolol and losartan. Am J Hypertens. 2005;18:1060-66.

5. Fonarow GC, Gawlinski A, Moughrabi S, et al. Improved treatment of coronary heart disease by implementation of a Cardiac Hospitalization Atherosclerosis Management Program (CHAMP). Am J Cardiol. 2001;87:819-22. 